\section{Ethics requirement score}

Escore de exigência ética

The recent manuscript "Ethics Requirement Score: new tool for evaluating ethics in publications" is very interesting. ${ }^{(1)}$ Santos et al. reported that "although the Impact Factor of foreigner journals was considerably higher than that of the Brazilian publications, the results showed that the Impact Factor has no correlation with the proposed score". ${ }^{(1)}$ Indeed, the Impact Factor does not reflect anything on publication ethics. ${ }^{(2)}$ Many problematic articles (such as those with duplications and plagiarisms) are published in high Impact Factor journals. However, "Ethics Requirement Score" as the basis of publication ethics is also questionable. Data extraction only from "author's guidelines or instructions in each journal website" might not imply ethical quality of a journal. Some journals might indicate good ethical declarations but, truly, they might have an inappropriate ethical behavior. A more direct way to track ethical practice might be the assessment of actions taken by journals towards ethical problems by the correction or retraction of problematic publication. ${ }^{(3)}$

Viroj Wiwanitkit

Surin Rajabhat University, Surin, Tailândia.

\section{REFERENCES}

1. Santos LG, Fonseca AC, Bica CG. Ethics Requirement Score: new tool for evaluating ethics in publications. Einstein (Sao Paulo). 2014;12(4):405-12.

2. Wiwanitkit S, Wiwanitkit V. "Broader impacts" or "responsible research and innovation"? Sci Eng Ethics. 2014;20(4):1149-50.

3. Ou S, Wiwanitkit V. Response to "The ethics of scholarly publishing: exploring differences in plagiarism and duplicate publication across nations". J Med Libr Assoc. 2015;103(1):57. 